\title{
META-ANALYSIS: THE EFFECT OF REMINISCENCE THERAPY ON FUNCTIONAL COGNITIVE IN ELDERLY WITH DEMENTIA
}

\author{
Ayu Fitriyaningsih \\ Masters Program in Public Health, Universitas Sebelas Maret
}

\begin{abstract}
Background: Cognitive impairments frequently occur among the elderly, with the global occurrence increasing to unprecedented levels in the elderly population. Dementia is an irreversible condition presenting not only cognitive dysfunction, depression, and behavioral and psychological symptoms of dementia, but also dysfunction in activities of daily living. Reminiscence is believed to be effective in improving the cognition and mood of demented people. This study aimed to examine the effect of reminiscence therapy on functional cognitive in elderly with dementia.

Subjects and Method: A systematic literature search was conducted in multiple databases including Science Direct, AJOT, PubMed, Google Scholar, Springer Link, and complemented by cross-referencing to identify randomized control trial published from 2016 to 2021. The following search terms were used: "reminiscence therapy" or "reminiscence" AND "cognition" or "cognitive function" AND "dementia". Study instrument for assessing functional cognitive was mini mental state examination (MMSE). The systematic review was carried out according to the PRISMA guidelines. Data analysis were performed using RevMan 5.3.

Results: A meta-analysis included 9 studies from United States, Japan, Korea, and Turkey. This study showed that reminiscence therapy improved functional cognitive in the elderly with dementia (Standardized mean difference $=0.45 ; 95 \% \mathrm{CI}=0.11$ to 0.80 ; $\mathrm{p}=0.010$ ).
\end{abstract}

Conclusion: Reminiscence therapy improves functional cognitive in the elderly with dementia.

Keywords: reminiscence therapy, cogitive function, dementia

\section{Correspondence:}

Ayu Fitriyaningsih. Masters Program in Public Health, Universitas Sebelas Maret. Jl. Ir. Sutami 36A, Surakarta 57126, Central Java. Email: ayufitriyao3@students.uns.ac.id. Mobile: +6281228530733 . 